\title{
USING SOCIAL EPIDEMIOLOGY TO UNDERSTAND WHO STAYS BLIND AND WHO GETS OPERATED FOR CATARACT IN A RURAL SETTING
}

\author{
Girija E. Brilliant ${ }^{1.2}$ and Lawrence B. Brilliant ${ }^{2}$ \\ 'Seva Foundation, Chelsea, MI 48118 and 'Department of Epidemiology, University of Michigan, \\ Ann Arbor, MI 48109, U.S.A.
}

\section{INTRODUCTION}

Although worldwide data is incomplete, cataract is probably the leading cause of blindness in the world [1]. A recent review of global data on blindness suggests that of the estimated 42 million blind in the world, approx. 17 million are blind from cataract [2].

It is particularly tragic that cataract should cause such a large share of blindness because the surgical techniques for removing lenticular opacities are relatively simple, inexpensive and have been practised safely for many years in a variety of settings. It is, however, in precisely those areas of the world where the prevalence of cataract blindness is highest, that access to cataract surgery is limited.

Even when cataract surgery is available, it is often underutilized. A recent study in India showed that less than $20 \%$ of cataract patients advised to have surgery actually came for the operation within a 2 year follow-up period [3]. In the United States, patients who have refused surgery for operable cataract form the second largest group of blind, after glaucoma [4]. A study of cataract blind in New York indicated that less than half of the cataract patients referred for the procedure ever had the operation [5].

This underutilization may be traced to several obstacles or barriers. The first barrier, especially important in developing countries, is access. The majority of cataract blind in developing countries live in rural areas, whereas most ophthalmic surgeons live in large cities [6]. The second barrier is education. Cataract is often popularly regarded as an irreversible and unavoidable result of the aging process. Misconceptions about cataract surgery and its outcome are often widespread, even when the patient is nominally aware of the procedure.

Finally, even when the cataract patient is well informed about his or her condition and surgery is available, the patient may be reluctant to elect surgery because of real economic and logistical obstacles, or because of perceptions about the lack of opportunities for surgery.

Cataract is thus not only the major cause of avoidable blindness, it is also a condition which poses serious geographic, educational, socio-economic and logistical challenges to any program aimed at reducing the prevalence of needless blindness. Information on what factors determine who utilizes cataract surgery is therefore essential to help deliver sight restoring surgery to this large under-served blind population.

\section{METHODS}

The Nepal Blindness Survey was a multipurpose, interdisciplinary study of the distribution and determinants of blindness in Nepal. Conducted under the auspices of the Government of Nepal and World Health Organization (WHO), the survey was the first activity of the Nepal Blindness Project, which has the goal of reducing preventable and curable blindness and enhancing national self-sufficiency in eye health care.

The Nepal Blindness Survey was designed to gather data on a large sample of the Nepalese population which could be used to estimate the prevalence, causes, and correlates of blindness for the country. The 39,887 subjects examined in the Nepal Blindness Survey were drawn from 105 sample sites across the country, using a two-stage area probability sample within twelve sampling strata. The sample selection used geographic stratification to disperse the sample across Nepal's 75 districts.

The survey was conducted in two phases: enumeration and examination. In the enumeration phase, all usual village residents were identified, and information on environmental, household and village characteristics was collected. After enumeration was completed, the eye examinations were performed at a central site in the village. The overall response rate was $93.5 \%$. The sample design, field methodology and ophthalmic protocols are described in detail elsewhere [7]. Briefly, visual acuity was tested by an ophthalmic assistant using a tumbling $E$ card and each person was examined by an ophthalmologist in a darkened room using a battery-powered focused light source and a $2.5 \times$ head-mounted loupe. The ophthalmic examination included objective clinical signs as well as clinical impressions. Individuals with visual acuity less than $6 / 18$ received a supplementary ophthalmic examination including pupil dilatation. Inter-observer agreement on the diagnosis of cataract was excellent [8]. Following eye examinations, interviews with cataract patients were conducted by team physicians in Nepalese.

These interviews investigated the factors which determine who has received cataract surgery in the past and who has not. Of the 39,887 subjects selected 
in the probability sample survey, 95 previously operated cataract patients and 254 unoperated cataract blind were interviewed about their beliefs and practices regarding cataract and the decision-making process leading to surgery. This study on cataract and aphakia had four objectives:

(1) To describe the number and geographic distribution of the aphakics, and investigate the effectiveness of previous cataract surgery in Nepal.

(2) To describe current beliefs and practices about cataract in this population.

(3) To identify correlates of awareness of cataract surgery among those who could benefit from it.

(4) To identify factors which distinguish those who had been operated on for cataract from those who were aware of the procedure but had not had their sight restored.

\section{RESULTS}

\section{Cataract and visual acuity}

Cataract is the leading cause of blindness in Nepal, accounting for more than two-thirds of blindness and more than $80 \%$ of all avoidable blindness. There are an estimated 397,000 people with cataract in Nepal today ( 2.8 cases per 100 population or $2.8 \%$ ) of whom 78,605 are curably blind [9].

Cataract is not uniformly distributed in Nepal. Age-sex standardized prevalence rates range from $<0.5 \%$ in one mountain village to $7.5 \%$ in one plains (Terai) village. More than one-third of Nepalese men and women over the age of 65 have cataract. For all age groups, cataract prevalance was $2.4 \%$ for males and $2.8 \%$ for females. By the WHO definition of blindness (visual acuity $<3 / 60$ in the better eye), approx. $20 \%$ of those with some degree of lenticular opacity were blind from their cataracts. It is helpful to think of this measure as the 'case-blindness ratio' similar to a 'case-fatality ratio' used in assessing the pathogenicity of other diseases. The case-blindness ratio varies widely by geographic and socioeconomic group, reflecting both severity of the disease as well as the utilization of successful curative surgery.

\section{Surgical coverage in Nepal}

There are an estimated 37,289 living Nepalese (3 per 1000 population) who have been operated on for cataract. In order to assess the rate at which cataract blindness in Nepal is being treated surgically, a measure was developed called the 'surgical coverage ratio' which refers to the percent of those in need of cataract surgery who have received it. The numerator of this ratio consists of all those who have been operated for cataract (aphakics); the denominator contains both operated and unoperated cataract blind, because at a given point in time, both operated and unoperated cataract blind formed the pool of potential candidates for surgery. For all Nepal, the surgical coverage ratio is:

$$
\frac{37,289 \text { aphakic }}{\begin{array}{c}
37,289 \text { aphakic } \\
+69,318 \text { unoperated cataract blind }
\end{array}}=35 \%
$$

This ratio varies by gender, literacy and geography. Surgical coverage was higher for males $(43 \%)$ than for females $\left(30^{\circ}\right)$. Of cataract patients who were literate before blindness. $65^{\circ}$ had had sight restoring surgery compared to $32^{\circ}$ of the illiterate. Surgical coverage was $54_{0}^{\circ}$ in urban areas, but only $32^{\circ}{ }_{0}$ in rural areas. In rural areas, the surgical coverage was highest in areas which had easy access to major eye centers such as the Indian eye hospital in Sitapur. Surgical coverage was lowest in the Eastern and Central Hills and Terai. which have difficult access and are under-served by eye care facilities. Figure 1 shows the surgical coverage ratio in each of the 12 rural strata used in the Nepal Blindness Survey.

\section{Effectiveness of previous cataract surgery}

Ninety-five subjects with cataract who were interviewed in the cataract and aphakic study had been operated on by an ophthalmic surgeon. Sixty percent of these respondents had been operated in Nepal. and $40 \%$ in India. Only $30 \%$ of the opcrations in Nepal had been performed in hospitals, compared to $70^{\circ}$ of the operations in India. The remainder were done in eye camps. The increasing availability of cataract surgery in Nepal during recent years is reflected in the finding that over two-thirds of the aphakics were operated within the past 5 years.

The typical aphakic had walked for nearly 2 days to reach the place where they had received cataract surgery; almost all had been accompanied by a relative. Social support was an important precondition for acceptance of cataract surgery. Ninety-four percent of the operated said they discussed having the operation with relatives before surgery. No one came for surgery in the face of family opposition. Nearly $20 \%$ of those operated were still blind after surgery ( $\mathrm{V} / \mathrm{A}<3 / 60$ in the best eye). While half had received corrective glasses at the time of surgery, less than one-third were currently wearing them. As a result, $40 \%$ of the aphakic individuals were functionally blind but could have improved vision with the provision of corrective glasses.

The survey identified 13 individuals who had undergone a traditional treatment for cataract known as 'couching', in which the lenticular opacity is dislodged into the vitreous humour by the use of a thorn or handmade "instrument". Ten of these individuals $(77 \%)$ remained blind after couching, reflecting the dangers of the procedure. This traditional treatment was often undertaken due to local availability as opposed to preference for traditional rather than modern treatment. In fact, six individuals who had been couched in one eye were surgically operated for cataract in the second eye after ophthalmic surgery became available in their area.

\section{Beliefs about cataract surgery in Nepal}

A total of 95 aphakics and 254 unoperated cataract blind were included in the study of beliefs and practices about cataract. The age distribution of these 354 subjects was similar for both sexes; over $55^{\circ}$ of both men and women were 65 years or older. Twentytwo percent of the men were literate compared to $0.2 \%$ of the women. The distribution by religion and caste in this sample was similar to the nationwide estimates from the Nepal Blindness Survey [9].

Among the unoperated cataract patients inter- 


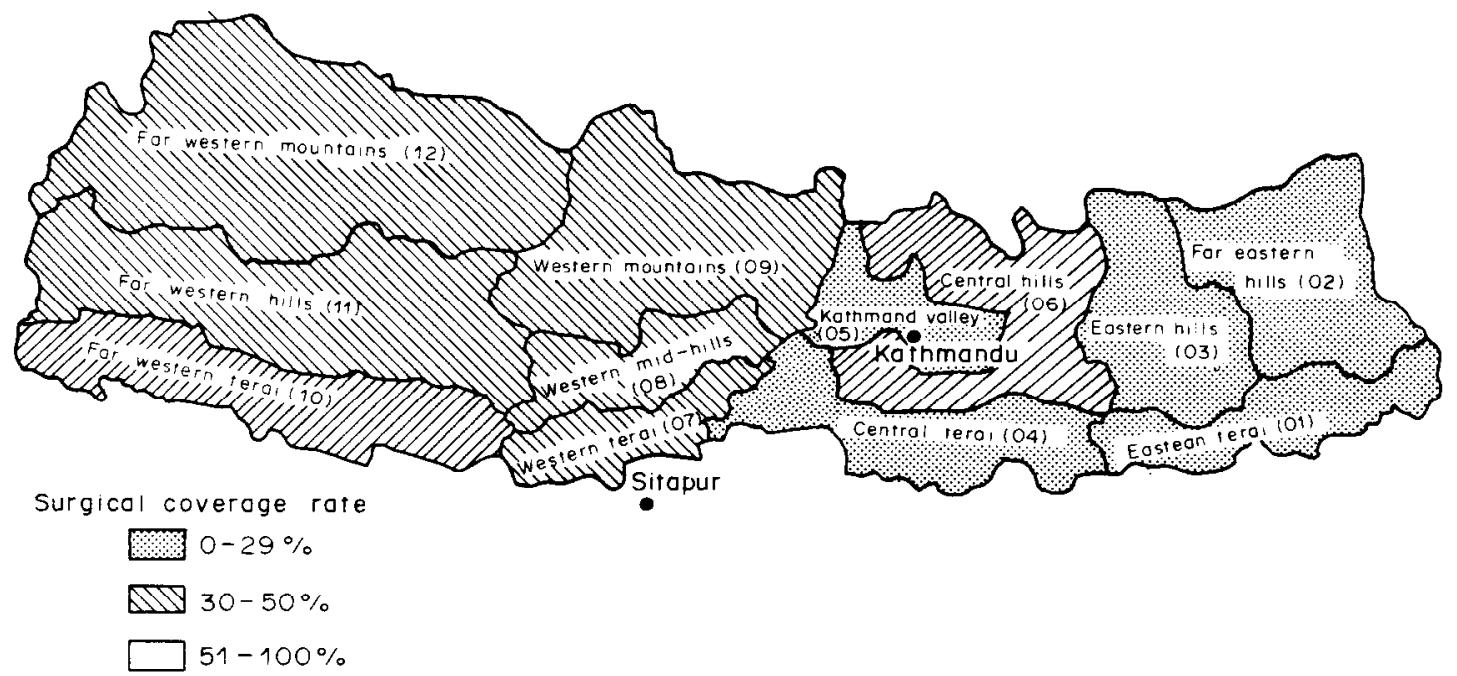

Fig. 1. Surgical coverage of cataract in Nepal by sampling strata.

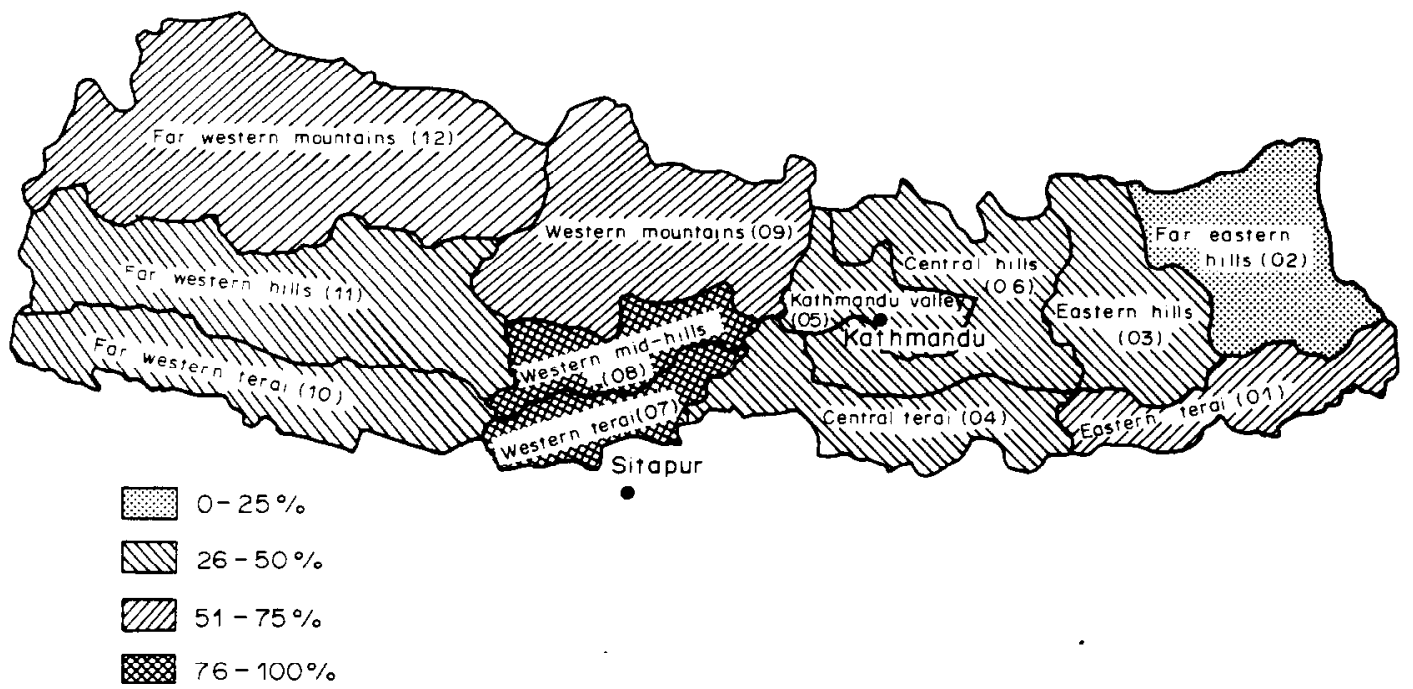

Fig. 2. $\%$ Unoperated cataract patients aware of surgery, by sampling strata.

viewed. approximately half $(52 \%)$ were aware of cataract surgery. Awareness of cataract surgery was not uniformly distributed in the country. Figure 2 shows the percentage of cataract blind who were aware of surgery for each rural geographic strata in the survey. Awareness was highest near the Indian town of Sitapur. which has been providing cataract surgery for over 20 years. It was lowest in the Far Eastern area of the country, where transportation, communication and health resources are severely limited.

The level of information about cataract surgery in this rural population was minimal even amongst those who were aware that the procedure existed. Over $80^{\circ}{ }_{0}(210)$ did not know if the operation was painful: less than half (122) believed the operation could restore sight. with the other half undecided.

*The importance of economic considerations in a marginal economy such as Nepal is also reflected in the finding that the most frequent reason given by cataract patients for family rejection after onset of blindness was loss of economic productivity.
Many could not recall how they first learned about the operation. Less than one-quarter (56) could name cataract as the cause of their visual impairment. While many attributed their blindness to old age or weakness, the majority could not name any specific cause.

Two-thirds of those unoperated cataract blind who were aware of surgery said they would like to have sight-restoring surgery. When asked why they had not yet undertaken surgery, the most frequent reason, cited by $38 \%$, was economic*. We estimate that the average cost for food for two people to travel to surgery in Nepal, remain for the operation, and return home is $\$ 20$. Since the annual per capita income in Nepal is less than $\$ 100$, the economic costs to a poor family of even a free operation can be one-fifth of per capita income. The second most frequent reason for delay in electing surgery (cited by $17 \%$ of the respondents) dealt with access to care, either due to lack of transportation to the surgical facility or lack of a companion to bring the visually impaired patient to the hospital or eye camp. In Nepal, cataract surgery is often undertaken only 
Table 1. Reasons for delay in electing cataract surgery

\begin{tabular}{lrr}
\hline Reason & $N$ & \multicolumn{1}{c}{$n$} \\
\hline Cost of procedure or food & 48 & 37.5 \\
Lack of transportation or companion & 22 & 17.2 \\
Only learned recently & 18 & 14.1 \\
Fear (blindness, death) & 8 & 6.3 \\
Too old & 6 & 4.7 \\
Can still see & 6 & 4.7 \\
Other & 13 & 10.1 \\
Don't know & 7 & 5.4 \\
Total & 128 & 100.0 \\
\hline
\end{tabular}

when the cataract is fully mature and vision has become severely impaired. As a result, the blind patient must be accompanied to surgery, and the need for a companion is another burden on the family. Psychological factors such as fear of surgery or family opposition were less frequently cited as reasons for delay in electing cataract surgery. Table 1 summarizes the major reasons cited for delay in electing cataract surgery in Nepal.

\section{Awareness of cataract surgery}

Because awareness of an elective procedure is the essential prerequisite to its acceptance, the study attempted to identify ways in which those who were aware of cataract surgery differed from those cataract patients who did not know about it. Variables from the community, household and individual level which displayed a statistically significant association with awareness of cataract surgery using the odds ratio are presented in Table 2 . These analyses are shown separately for men and women, because gender was an important correlate of awareness of cataract surgery. Sixty-one percent of male cataract patients were aware of surgery compared to $46^{\circ}$ of females. In traditional societies, sex roles have profound implications for knowledge about and access to health resources.

Overall, those who had learned about surgery were more likely to have access to other community resources such as postal service and secondary schools. to know the cause of their visual impairment to be cataract and to believe that illness could be prevented. Other correlates of awareness of cataract surgery were gender-specific. Males were more likely to know about surgery if a physician were available in the community while women were more likely to know about cataract surgery if traditional healers were absent from the community. Some possible reasons for this are presented in the Discussion section. In addition, women were more likely to know about the surgery if they came from families that owned and used modern objects such as radios or wrist watches.

In order to control for possible confounding effects among the correlates of awareness of cataract surgery, logistical regression was done. All of the variables which had a statistically significant univariate association with awareness of surgery maintained significance when incorporated into a full logistical model [10].

\section{Utilization of cataract surgery}

Another objective of the study was to identify ways in which individuals who had elected cataract surgery differed from those who knew about the procedure but had not yet undertaken it. In general, there

Table 2. Correlates of awareness of cataract surgery

\begin{tabular}{|c|c|c|c|c|c|c|}
\hline \multirow[b]{2}{*}{ Predictor } & \multicolumn{2}{|r|}{ Male } & \multicolumn{2}{|r|}{ Female } & \multicolumn{2}{|c|}{ Total } \\
\hline & $N$ & Odds ratio & $N$ & Odds ratio & $N$ & Odds ratio \\
\hline \multicolumn{7}{|l|}{ Community level } \\
\hline 1. Postal service available & 86 & $3.3^{* *}$ & 164 & $1.9^{*}$ & 250 & $2.1^{* *}$ \\
\hline 2. Secondary school available & 86 & 1.8 & 164 & 1.6 & 250 & $1.6^{*}$ \\
\hline 3. Ayurvedic practitioner available & 86 & 1.1 & 164 & $0.4^{* * * *}$ & 250 & 0.6 \\
\hline 4. Physician available & 86 & $4.3^{*}$ & 164 & 1.5 & 250 & 2.0 \\
\hline \multicolumn{7}{|l|}{ Household level } \\
\hline 1. Watch ownership & 83 & 1.1 & 164 & $3.8^{*}$ & 247 & $2.3 *$ \\
\hline 2. Radio ownership & 86 & 1.2 & 164 & $8.9^{* * *}$ & 250 & $3.6 * *$ \\
\hline 3. Radio use & 79 & 0.9 & 154 & $7.2^{* * *}$ & 233 & 3.3 \\
\hline \multicolumn{7}{|l|}{ Individual level } \\
\hline 1. Sex & NA & NA & NA & NA & 250 & $1.8 *$ \\
\hline 2. Perceived preventability of illness & 54 & $12.8^{* * *}$ & 123 & $19.3^{* * *}$ & 177 & $17.4 * * *$ \\
\hline 3. Understanding cause of visual impairment is cataract & 86 & $4.7^{* *}$ & 164 & $3.2^{* *}$ & 250 & $3.8^{* *}$ \\
\hline
\end{tabular}

${ }^{*} 0.01<P \leqslant 0.05 ; * * 0.001<P \leqslant 0.01 ; * * P \leqslant 0.001$

Tahle 3. Correlates of acceptance of cataract surgery in Nepal

\begin{tabular}{|c|c|c|c|c|c|c|}
\hline & \multicolumn{2}{|c|}{ Male } & \multicolumn{2}{|c|}{ Female } & \multicolumn{2}{|c|}{ Total } \\
\hline & $N$ & Odds ratio & $N$ & Odds ratio & $N$ & Odds ratio \\
\hline \multicolumn{7}{|l|}{ Community level } \\
\hline 1. Physician available & 99 & 0.7 & 124 & $0.2^{*}$ & 223 & 0.5 \\
\hline 2. Residence near major eye hospital & 99 & 1.5 & 124 & $3.1^{*}$ & 223 & $2.2^{*}$ \\
\hline \multicolumn{7}{|l|}{ Household level } \\
\hline 1. High economic status & 51 & 2.4 & 85 & $2.9^{*}$ & 136 & $2.4^{*}$ \\
\hline 2. Watch ownership & 99 & 1.8 & 124 & $2.4^{*}$ & 223 & $2.0^{*}$ \\
\hline \multicolumn{7}{|l|}{ Individual leve! } \\
\hline 1. Age (Over 55 years) & 99 & $5.2 * *$ & 124 & 1.2 & 223 & $2.3^{*}$ \\
\hline 2. Literacy & 99 & 2.5 & & n.a. & 223 & $2.7^{*}$ \\
\hline 3. Relation to head of household & 98 & 1.8 & 122 & $2.7^{*}$ & 220 & $2.3^{* *}$ \\
\hline 4. Knowing another operated person & 87 & 1.3 & 101 & $3.3^{* *}$ & 188 & $2.1^{* *}$ \\
\hline
\end{tabular}

${ }^{*} 0.01<P \leqslant 0.05 ; * 0.001<P \leqslant 0.01 ; * * P \leqslant 0.001$. 
were fewer differences between these two groups, but the differences which existed were also sex-linked. Table 3 summarizes the correlates of utilization of surgery. Among males, those who had been operated for cataract were older and more likely to be literate than men who were aware of surgery but unoperated. Females who were operated came from richer families (using both traditional and modern measures of wealth), were more likely to be central in the family structure than distantly related, were more likely to know another operated person and lived closer to a center of ophthalmic care than unoperated women aware of surgery. Local community resources did not appear to play an important role in predicting actual use of cataract surgery. All of these correlates maintained statistical significance after controlling for confounding through the use of logistical regression.

\section{DISCUSSION}

The study results reflect the importance of community, family and individual traits in learning about the availability of cataract surgery and making the decision to undertake it. The findings have important implications for health education and planning efforts for the prevention of blindness. The results indicate a need for basic health education about cataract in Nepal. Educational messages should inform the rural population that cataract is a common cause of visual impairment in those over 40 , that cataract can be cured by surgery and that surgery is effective and relatively painless. It is important to inform villagers that surgery can be done prior to the time when vision is seriously impaired and that traditional treatment by couching is dangerous.

Village health workers appear to be effective educational agents; the use of radio and newspapers would reach only a small, affluent elite. The finding that household variables such as ownership and use of modern objects were predictive of awareness of surgery for women, but not men, reflects the almost exclusively domestic role of women in rural Nepal. This underscores the need for health education that will reach the female cataract patient through a domestic rather than community channel of communication. Successfuly operated cataract patients have been used as health motivators in South India and the results suggest that they would be effective here as well.

Other studies $[11,12]$ have shown that in traditional societies, men are more likely to use physician services than women, and this may explain the association in the study between physician availability and awareness of surgery in men. Since women are more likely to use traditional healers and since the traditional treatment for cataract in Nepal does not include surgical referral, the presence of such healers may actually hinder women from learning about the operation. However, if traditional healers are informed about the availability of cataract surgery, they could be useful in educating female cataract patients; physicians could be more effective in informing males. Health education efforts should be aimed both at the cataract patient and the family, as the decision to undetake surgery is made only with family approval. The uneven distribution of awareness of cataract surgery shown in Fig. 2 indicates that health education efforts must be intensified in those geographic areas where cataract prevalence is high but awareness is low.

Postal service and schools link the isolated village with the country around it, as does radio use: both broaden the villagers' horizons. The findings suggest that such basic community resources facilitate learning about a health innovation such as cataract surgery for both men and women. The finding that those who knew that their visual impairment was due to cataract were more likely to know about surgery suggests that when the agent for a physical condition is identified in "modern" terms, information about a 'modern' treatment will be more readily sought out and remembered. The association between awareness of surgery and belief in prevention of illness also indicates a more cosmopolitan attitude, reflecting the influence of education and mass media in the community [13]. Health education campaigns would increase awareness of cataract surgery and would also develop an expectation that cataract can and should be treated. Cataract might then no longer be perceived as an inevitable, irreversible, life-long curse of darkness. The provision for free or low-cost aphakic spectacles after surgery and on a replacement basis would ensure that those patients who obtain cataract surgery would be more fully returned to a sighted, productive life.

It appears that cataract surgery is more readily provided to men regardless of family wealth, centrality in family structure, or access to care. Women, on the other hand, appear to receive surgery if barriers of distance or cost are minimal, or if they are in an important position in the family. Local community resources did not appear to play an important role in predicting actual use of cataract surgery.

Since life expectancy in Nepal is increasing, and the prevalence of cataract is higher in women than men, it is likely that in the future elderly women will form an increasingly larger share of the unoperated cataract population. It is thus important to develop an eye health program which will minimize barriers to cataract surgery most problematic to elderly women. Since family wealth and access to care are important correlates of use of cataract surgery in women, every attempt must be made to minimize barriers of cost and distance. Measures such as provision of free food after surgery, and use of eye camps to bring eye care close to the villagers are now being instituted in Nepal. It is our hope that they will greatly increase utilization of cataract surgery and reduce the burden of this needless blindness.

Acknowledgements-This study was a part of the Nepal Blindness Survey which was conducted under the auspices of the World Health Organization and the Government of Nepal. Funds came from a generous grant from the Government of the Netherlands to WHO. Support was aiso provided by the SEVA Foundation, the American Foundation for the Blind, the University of Michigan and The Prevention of Blindness Programme of WHO. The research was originally suggested by Dr G. Venkataswamy. We thank Drs N. Grasset and R. P. Pokhrel for their help and encouragement in carrying out this research. An early draft of this paper was presented at the 1983 meetings of the American Public Health Association. 


\section{REFERENCES}

1. Maitchouk I. F. Data on blindness. Vision 1, 99, 1982.

2. Maitchouk I. F. Two WHO targets: trachoma and cataract. Wld Hith January, 18-19, 1983

3. Venkataswamy $G$. and Brilliant $G$. Social and economic barriers to cataract surgery in rural south India. A preliminary report. Visual Impairment and Blindness, pp. 405-508, 1981

4. Newell F. Ophthalmology. C. V. Mosby, St Louis, 1978.

5. Miller I. Resistance to Cataract Surgery. American Foundation for the Blind, Ncw York, 1964.

6. Eye Health in Southeast Asia, p. 3, 1978

7. Brilliant L. B., Grasset N., Pokhrel R. P., Kolstad A., Lepkowski J. M., Brilliant G. E. and Hawks W Association among cataract prevalence, sunlight hours, and altitude in the Himalayas. Am. J. Epid. 118, 250-264, 1985.

8. Brilliant L. B., Lepkowski J. M. and Musch D. C. Reliability of ophthalmic diagnoses in an epidemiologic survey. Am. J. Epid. 118, 265-279, 1985. 9. The Epidemiology of Blindness in Nepal. The Final Report of the Nepal Blindness Survey, Vol. II. WHO, Kathmandu, Nepal. In press.

9. The Epidemiology of Blindness in Nepal. The Final Report of the Nepal Blindness Survey, Vol. II. WHO, Kathmandu, Nepal. In press.

10. Brilliant $\mathbf{G}$. Determinants of cataract surgery utilization in Nepal. Unpublished doctoral dissertation, University of Michigan, Ann Arbor, Mich., 1983.

11. Lieban R. Sex differences and cultural dimensions of medical phenomenon in a Philippine setting. In Culture and Curing (Edited by Morely P. and Walters R.) Allen, London, 1978.

12. Morsy S. Health and illness as symbols of social differentiation in an Egyptian village. Anthrop. Q. 53, 153-161, 1980.

13. Rogers E. and Shoemaker F. Communication and Inmovations: A Cross Cultural Approach. Free Press, New York, 1971 